\title{
UJI AKTIVITAS TABIR SURYA EKSTRAK DAUN BELIMBING HUTAN (Cnestis palala (Lour.) Merr)
}

\author{
Chairunnisa Arbain*, Nur Mita, Laode Rijai \\ Laboratorium Penelitian dan Pengembangan FARMAKA TROPIS, Fakultas \\ Farmasi Universitas Mulawarman, Samarinda, Kalimantan Timur \\ *Email: c.nisa31@yahoo.co.id
}

\begin{abstract}
ABSTRAK
Belimbing hutan (Cnestis palala (Lour.) Merr) merupakan salah satu spesies tumbuhan di Kalimantan Timur banyak digunakan dalam pengobatan. Akan tetapi belum ada laporan mengenai aktivitas tabir surya. Penelitian ini bertujuan untuk mengetahui rendemen ekstrak, aktivitas tabir surya, dan kategori tabir surya. Penelitian ini menggunakan ekstrak dengan perbedaan waktu perendaman maserasi yaitu 24 jam, 48 jam dan 72 jam kemudian dianalisis dengan spektrofotometri UvVis pada ekstrak tersebut. Berdasarkan nilai \%Te dan \% Tp, ekstrak belimbing hutan pada waktu 24 jam, 48 jam dan 72 jam memiliki aktivitas tabir surya masuk dalam kategori sunblock dan perlindungan ekstra dalam efektivitas tabir surya.
\end{abstract}

Kata Kunci : Belimbing Hutan, Tabir surya, \% Te, \% Tp

\begin{abstract}
Cnestis Palala. (Lour) Merr in East Kalimantan widely used as medicine. However, there is not yet report on its antioxidant activity. This study aims were to determine the yield of extracts, sunscreen activity and category sunscreen of Cnestis Palala. (Lour) Merr. This study was used the extract by the time difference submersion maserasi namely 24 hours, 48 hours and 72 hours later analyzed with spektrofotometri Uv-Vis on the extract. Based on the value of \% Te and \% Tp, extract carambola is the at the time 24 hours, 48 hours and 72 hours have activities sunscreen in the category of sunblock and the protection of the extra in the effectiveness of sunscreen.
\end{abstract}

Keywords : starfruit leaves forest, sunscreen, \%Te, \%Tp 


\section{PENDAHULUAN}

Pemaparan sinar ultraviolet dari matahari secara kronik akan mengakibatkan perubahan struktur dan komposisi kulit dan stress oksidatif pada kulit. Efek yang ditimbulkan dapat berupa perubahan-perubahan akut seperti eritema, pigmentasi dan fotosensitivitas, maupun efek jangka panjang berupa penuaan dini dan keganasan kulit. Preparat tabir surya dianjurkan penggunaannya untuk mencegah atau meminimalkan efek sinar UV yang berbahaya terhadap kulit biasanya dapat diminimalkan dengan penggunaan bahan-bahan yang bersifat UV protektif (Susanti, 2012).

Efektifitas dari suatu sediaan tabir surya dapat ditunjukkan salah satunya adalah dengan nilai sun protection factor (SPF), yang didefinisikan sebagai jumlah energi UV yang dibutuhkan untuk mencapai minimal erythema dose (MED) pada kulit yang dilindungi oleh suatu tabir surya, dibagi dengan jumlah energi UV yang dibutuhkan untuk mencapai MED pada kulit yang tidak diberikan perlindungan. MED didefinisikan sebagai jangka waktu terendah atau dosis radiasi sinar UV yang dibutuhkan untuk menyebabkan terjadinya erythema.

Belimbing hutan (Cnestis palala (Lour.) Merr) merupakan tumbuhan yang banyak terdapat didalam hutan dan pinggiran sungai. Bagian yang sering digunakan mulai dari daun, akar, kulit batang hingga batangnya. Daun belimbing hutan mengandung saponin, asam amino, karbohidrat, senyawa fenolik, glikosida, tanin, pati, glikosida cyanogenic, flavonoid, triterpenoid dan kumarin. Flavanoid dan tannin merupakan beberapa senyawa yang memiliki potensi sebagai tabir surya (Mokodompit, 2013).

Maserasi adalah proses pengekstrakan simplisia dengan menggunakan pelarut dengan beberapa kali pengocokan atau pengadukan pada temperatur ruangan (kamar). Secara teknologi termasuk ekstraksi dengan prinsip metode pencapaian konsentrasi pada keseimbangan. Maserasi kinetik berarti dilakukan pengadukan yang kontinu (terus-menerus). Remaserasi berarti dilakukan pengulangan penambahan pelarut setelah dilakukan penyaringan maserat pertama dan seterusnya (DITJEN POM, 2000). 
Senyawa metabolit sekunder merupakan sumber bahan kimia alami yang dapat ditemukan di alam untuk dijadikan sebagai rujukan untuk pengembangan obat-obatan khususnya obat baru atau untuk menujang berbagai kepentingan industri. Bahan ini tidak akan pernah habis dan terus akan tercipta dengan struktur molekul yang mengalami interkonversi sejalan dengan perkembangan zaman. Dengan demikian senyawa yang bersumber dari alam akan terus ada tercipta baik yang sudah pernah ditemukan maupun yang baru dan belum diketemukan (Darminto, 2009).

Senyawa tabur surya sintetik (sekunder) memiliki fungsi menangkap radikal bebas dan menghentikan reaksi berantai, berikut adalah contoh senyawa tabir surya sintetik: saponin, senyawa fenolik, flavanoid, tanin.

Tujuan dari penelitian ini adalah untuk mengetahui rendemen ekstrak belimbing hutan (Cnestis palala (Lour.) Merr), mengetahui aktivitas tabir surya ekstrak daun belimbing hutan (Cnestis palala (Lour.) Merr) dan mengetahui aktivitas tabir surya ekstrak daun belimbing hutan (Cnestis palala (Lour.) Merr) dalam berbagai variasi konsentrasi yang dikategorikan sebagai tabir surya.

\section{METODE PENELITIAN}

\section{Bahan}

Aquades, Daun Belimbing hutan (Cnestis palala (Lour.) Merr), Metanol.

\section{Peralatan}

Seperangkat alat maserasi, Spektrofotometer Uv-Vis, desikator, rotary evaporator, timbangan analitik.

\section{Prosedur}

\section{Penyiapan Sampel}

Sampel yang digunakan adalah Daun Belimbing hutan (Cnestis palala (Lour.) Merr) yang masih segar dan tidak rusak. Tahap awal adalah pengumpulan bahan. Setelah pengumpulan bahan, dilakukan sortasi basah dengan menyeleksi bagian tanaman yang tidak digunakan seperti kotoran dari luar. Kemudian ditimbang dan dicuci dengan air mengalir. Dirajang dan dikeringkan sampel dengan cara diangin- 
anginkan pada suhu kamar dan terlindung dari cahaya matahari. Dilakukan sortasi kering dengan cara menyeleksi pengotor yang mungkin terikut, lalu disimpan.

\section{Ekstraksi Sampel}

Simplisia Daun Belimbing hutan (Cnestis palala (Lour.) Merr) dibagi kedalam 3 toples diekstraksi dengan metode maserasi menggunakan pelarut metanol sehingga diperoleh bagian residu dan bagian maserat. Proses maserasi dilakukan dalam wadah yang tertutup rapat (toples). Toples didiamkan selama 24 jam, 48 jam dan 72 jam dengan sesekali diaduk. Proses maserasi diulangi beberapa kali sampai pelarut metanol berwarna jernih. Ekstrak daun belimbing hutan kemudian dipisahkan dari pelarut metanol menggunakan rotary evaporator sehingga diperoleh ekstrak kental. Ekstrak kental selanjutnya diuapkan diatas water bath untuk memperoleh ekstrak kering dan kasar daun belimbing hutan.

Presentase rendemen diperoleh dengan cara membagi bobot akhir ekstrak dari hasil proses ekstraksi dengan bobot awal daun dikali 100\%.

\section{Uji Aktivitas dan Kategori Tabir Surya}

Ekstrak yang dihasilkan dalam proses maserasi, ekstrak kering yang telah diperoleh kemudian dibuat larutan stok dan variasi konsentrasi ekstrak yaitu dengan membuat 5 konsentrasi dengan menggunakan pelarut metanol dengan masingmasing 3 replikasi. Masing-masing konsentrasi ekstrak daun belimbing hutan diukur serapannya dengan menggunakan spektrofotometer UV-Vis pada panjang gelombang yang dapat menimbulkan eritema dan pigmentasi yaitu 292,5-372,5 nm.

Aktivitas tabir surya ekstrak daun belimbing hutan ditentukan dengan analisis deskriptif berdasarkan hasil perhitungan nilai persen transmisi eritema (\% Te) dan transmisi pigmentasi (\% Tp) yang telah diperoleh. Kemudian, nilai \% Te dan $\%$ Tp dari tiap seri konsentrasi tersebut dan dikategorikan ke dalam penilaian aktivitas tabir surya yaitu sunblock, proteksi ekstrak, suntan standar atau fast tanning. Ekstrak daun belimbing hutan dapat dikategorikan sebagai sunblock jika dapat menyerap hampir semua sinar UV-A dan sinar UV-B apabila memiliki persen Te $<1 \%$ dan persen Tp 3-40\%. Kategori proteksi ekstrak jika persen Te 1-6\% dan persen Tp 42-86\%. Kategori suntan standar jika persen Te 6-12\% dan persen Tp 45-86\%. Kategori fast tanning jika persen Te 10-18\% dan persen Tp 45-86\%. 


\section{HASIL DAN PEMBAHASAN}

\section{Ekstraksi Daun Belimbing Hutan}

Daun belimbing hutan yang digunakan dalam penelitian ini dibuat dalam bentuk simplisia. Simplisia merupakan bagian tanaman yang telah dikeringkan yang bertujuan agar daun dapat disimpan dalam waktu yang lama. Sampel yang digunakan dalam penelitian ini $270 \mathrm{~g}$. Proses pembuatan simplisia daun belimbing hutan meliputi beberapa tahapan, yakni pengumpulan daun lalu diambil bagian daunnya, pencucian dan sortasi basah, pengeringan dan sortasi kering, serta simplisia dipotong kecil-kecil agar proses penarikan senyawa pada saat pembuatan ekstrak daun maksimal.

Sampel kering kemudian dimaserasi dengan pelarut metanol sebanyak 6 L. Maserasi adalah cara penyarian sederhana dan cocok untuk simplisia daun, proses yang terjadi pada metode maserasi adalah proses difusi cairan penyari kedalam dinding sel dan masuk kerongga sel yang mengandung bahan aktif, zat aktif akan terlarut sehingga terjadi perbedaan konsentrasi antara konsentrasi zat aktif didalam dan diluar sel. Metanol merupakan pelarut yang baik sebagai cairan penyari dikarenakan bereaksi netral, murah serta dapat melarutkan senyawa-senyawa polar dan nonpolar. Kemudian ekstrak pekat diuapkan di waterbath dan diletakkan dalam desikator untuk mengeringkan sisa pelarut yang masih ada di ekstrak.

Perhitungan rendemen ini bertujuan untuk mengetahui jumlah ekstrak dalam hitungan persen. Sehingga dapat diketahui jika menggunakan x gram simplisia, akan didapatkan ekstrak sebesar y gram.

Tabel 1. Rendemen Ekstrak Daun Belimbing Hutan

\begin{tabular}{cccc}
\hline Waktu & Berat Awal & Berat Akhir & $\%$ Rendemen \\
\hline 24 Jam & 90 gram & 9,8 gram & $10,8 \%$ \\
48 Jam & 90 gram & 10,2 gram & $11,3 \%$ \\
72 Jam & 90 gram & 11,4 gram & $12,7 \%$ \\
\hline
\end{tabular}

Berdasarkan tabel diatas dapat dilihat bahwa, dari simplisia sebesar 90 gram dengan waktu maserasi 24 jam, 48 jam dan 72 jam berturut-turut didapatkan ekstrak 
sebanyak 9,8 gram, 10,2 gram, dan 11,4 gram sehingga persen rendemen yang dihasilkan yaitu 10,8 \%, 11,3\%, dan $12,7 \%$.

\section{Uji Aktivitas dan Kategori Tabir Surya}

Uji aktivitas tabir surya diawali dengan ekstrak yang dihasilkan dalam proses maserasi, ekstrak kering yang telah diperoleh kemudian dibuat larutan stok dan variasi konsentrasi ekstrak yaitu dengan membuat 5 variasi seri konsentrasi dengan menggunakan pelarut metanol dengan masing-masing 3 replikasi.

Metode nya yaitu masing-masing konsentrasi ekstrak daun belimbing hutan diukur serapannya dengan menggunakan spektrofotometer UV-Vis pada panjang gelombang yang dapat menimbulkan eritema dan pigmentasi yaitu 292,5-372,5 nm. Ekstrak yang dibuat dengan melarutkannya menggunakan metanol PA (Pro Analytic) kemudian dibuat variasi konsentrasi. Lalu ditembakkan dengan sinar UV Vis pada panjang gelombang 292,5-372,5 nm dengan spektrofotometri UV Vis, banyakmya nilai yang diabsorbsi pada panjang gelombang tertentu sebanding dengan banyaknya molekul yang menyerap sinar. Sinar yang diteruskan merupakan cahaya yang tidak diabsorbsi oleh sampel sehingga menghasilkan nilai T. Sehingga semakin kecil nilai T menunjukkan bahwa sinar yang diteruskan semakin kecil atau semakin banyak sinar yang diserap oleh sampel, sehingga dihasilkan nilai absorbansi yang kemudian diubah menjadi nilai \% (Gandjar, 2006).

Pengujian aktivitas tabir surya, dilakukan pada ekstrak metanol daun belimbing hutan dengan menggunakan spektrofotometer UV-Vis pada panjang gelombang 292,5-372,5 nm yang merupakan panjang gelombang yang dapat menyebabkan eritema dan pigmentasi.

Parameter yang digunakan yaitu \%Te dan \% Tp, yang merupakan persentase sinar UV pada panjang gelombang 292,5-372,5 nm yang diteruskan oleh sampel yaitu ekstrak metanol daun belimbing hutan. Parameter eritema dan pigmentasi ini merupakan gejala awal paparan sinar matahari pada kulit sebelum masuk pada keadaan yang lebih kuat seperti kanker kulit (melanoma). Oleh karena itu, parameter ini, perlu dicegah lebih awal sebelum gejala yang lebih parah muncul akibat paparan sinar UV. 
Senyawa yang berpotensi menunjukkan aktivitas tabir surya yang baik adalah bahan yang dapat menghasilkan nilai \%Te ataupun \% Tp yang kecil dengan konsentrasi yang paling rendah. Hal ini menunjukkan bahwa, senyawa tersebut dapat menghalangi sinar UV melewati kulit sehingga dapat mencegah terjadinya kerusakan kulit akibat sinar matahari.

Nilai \%Te dan \%Tp tersebut dapat dikategorikan ke dalam beberapa kategori tabir surya yaitu sunblock, proteksi ekstrak, suntan standar atau fast tanning (Balsam, 1972). Pemilihan variasi konsentrasi dimulai dari konsentrasi bahan yang masuk kedalam kategori terendah (fast tanning), yaitu bahan yang menghasilkan nilai \% $\mathrm{T}$ paling tinggi.

Tabel 2. Uji aktivitas dan Kategori Tabir Surya Daun belimbing hutan

\begin{tabular}{cccc}
\hline $\begin{array}{c}\text { Konsentrasi } \\
(\mathbf{p p m})\end{array}$ & \% Te & \% Tp & Kategori \\
\hline 50 & 16.574 & 14.722 & fast tanning \\
60 & 12.858 & 11.352 & fast tanning \\
70 & 9.869 & 8.459 & suntan standar \\
80 & 9.248 & 7.860 & suntan standar \\
90 & 3.722 & 2.846 & Proteksi ekstra \\
\hline
\end{tabular}

Hasil uji aktivitas tabir surya ekstrak daun belimbing hutan (Cnestis palala (Lour.) Merr.) memiliki aktivitas tabir surya terbaik pada konsentrasi 90 ppm dengan $\%$ Te 3,722\% dan $\%$ Tp 2,846\%. Pada hasil kategori tabir surya metanol daun belimbing hutan berturut-turut adalah kategori fast tanning pada konsentrasi 50 dan 60 ppm, suntan standar pada konsentrasi 70 dan 80 ppm, dan proteksi ekstra pada $90 \mathrm{ppm}$.

\section{KESIMPULAN}

Pada penelitian ini didapatkan kesimpulan bahwa Rendemen ekstrak daun belimbing hutan (Cnestis palala (Lour.) Merr.) pada waktu 24 jam, 48 jam dan 72 jam berturut-turut yaitu 10,8\%, 11,3\%, dan 12,7\%. Ekstrak daun belimbing hutan 
(Cnestis palala (Lour.) Merr.) memiliki aktivitas tabir surya terbaik pada konsentrasi 90 ppm dengan \%Te 3,722\% dan \%Tp 2,846\%. Kategori tabir surya metanol daun belimbing hutan berturut-turut adalah kategori fast tanning pada konsentrasi 50 dan 60 ppm, suntan standar pada konsentrasi 70 dan 80 ppm, dan proteksi ekstra pada $90 \mathrm{ppm}$.

\section{DAFTAR PUSTAKA}

Balsam, M. S., \& Sagarin, E. (Eds). 1972. Cosmetics: Science and Technology $2^{\text {nd }}$ Ed., Vols. 1-3. Interscience Publishers, Inc: New York.

Darminto. 2009 . Indentifikasi Senyawa Metabolit Sekunder Potensial Menghambat Pertumbuhan Bakteri Aeromonas hydrophyla dari Kulit batang Tumbuhan Aveccennia spp. Jurnal Chemica. Vol. 10 Nomor 2

DITJEN POM. 2000. Parameter Standar Umum Ekstrak Tumbuhan Obat. Jakarta

: Departemen Kesehatan RI Direktorat Jenderal Pengawasan Obat dan Makanan Direktorat Pengawasan Obat Tradisional

Gandjar, I.G., dan Rohman, A., 2006, Kimia Farmasi Analisis, Cetakan III, Pustaka Pelajar: Yogyakarta.

Mokodompit, A. N., Edy, H. J., dan Wiyono, D.2013. Penetuan Nilai Sun Protective Factor (SPF) Secara In vitro Krim Tabir Surya Ekstrak Etanol Kulit Alpukat. Jurnal Ilmiah Farmasi. 2. (3). 830-85

Susanti, Meri, Dachriyanus, Doni Permana Putra. 2012. Aktivitas Perlindungan Sinar UV Kulit Buah Garcinia mangostana Linn Secara In Vitro. Pharmacon. 13(2). 61-64 